\title{
Ultrasound-guided percutaneous needle biopsies of peripheral pulmonary lesions: diagnostic efficacy and risk factors for diagnostic failure
}

\author{
Qing Li, Li Zhang, Xinhong Liao, Shi Tang, Zhixian Li \\ Department of Diagnostic Ultrasound, First Affiliated Hospital of Guangxi Medical University, Nanning, China \\ Contributions: (I) Conception and design: Q Li; (II) Administrative support: Z Li, L Zhang; (III) Provision of study materials or patients: Z Li, X \\ Liao; (IV) Collection and assembly of data: Q Li, S Tang; (V) Data analysis and interpretation: Q Li; (VI) Manuscript writing: All authors; (VII) Final \\ approval of manuscript: All authors. \\ Correspondence to: Zhixian Li. Department of Diagnostic Ultrasound, First Affiliated Hospital of Guangxi Medical University, No. 6 Shuangyong \\ Road, Nanning 530021, China. Email: lizhixiangx2020@163.com.
}

\begin{abstract}
Background: To evaluate the diagnostic performance of ultrasound-guided percutaneous needle biopsy (US-PNB) for peripheral pulmonary lesions on the basis of the intention-to-diagnose principle and to identify the risk factors for diagnostic failure.

Methods: Patients with peripheral pulmonary lesions who underwent US-PNB in the Department of Ultrasound, the First Affiliated Hospital of Guangxi Medical University, China, from January 2017 to December 2019 were retrospectively enrolled in this study. The diagnostic accuracy, sensitivity, specificity, positive predictive value (PPV), and negative predictive value (NPV) of ultrasound-guided biopsy in peripheral pulmonary lesions was assessed. The proportion of diagnostic failure was calculated and the associated risk factors were identified.

Results: A total of 930 patients were enrolled in this study, including 957 US-PNBs. The overall diagnostic accuracy, sensitivity, and specificity was 90.3\% [864/957; 95\% confidence interval (CI): 0.88-0.922], 87.2\% (495/568; 95\% CI: 0.84-0.90), and 94.9\% (369/389; 95\% CI: 0.92-0.97), respectively. The PPVs and NPVs were 99.4\% (495/498; 95\% CI: 0.98-0.99) and 88.1\% (369/419; 95\% CI: 0.85-0.91), respectively. The diagnostic failure rate was $9.72 \%(93 / 957 ; 95 \%$ CI: 0.08-0.12). The independent risk factors for diagnostic failure were history of smoking [odds ratio (OR) 1.78, 95\% CI: 1.13-2.78], 18G biopsy needle (OR 2.97, 95\% CI: 1.06-8.30), and final clinical diagnosis of malignant lesions (OR 2.72, 95\% CI: 1.63-4.55).

Conclusions: US-PNB of peripheral pulmonary lesions show high diagnostic efficacy. A history of smoking, use of $18 \mathrm{G}$ biopsy needle, and final clinical diagnosis of malignant lesions are independent risk factors for diagnostic failure of US-PNB in peripheral pulmonary lesions. Identification of the independent risk factors for diagnostic failure can help reduce the diagnostic failure rate.
\end{abstract}

Keywords: Ultrasound; percutaneous needle biopsy (PNB); sensitivity and specificity; peripheral pulmonary lesions

Submitted Jul 15, 2021. Accepted for publication Sep 10, 2021.

doi: 10.21037/apm-21-2220

View this article at: https://dx.doi.org/10.21037/apm-21-2220

\section{Introduction}

Peripheral pulmonary lesions are defined as lesions located beyond the tertiary bronchi, and may be close to the pleura (1). The application of computed tomography
(CT) in recent years, especially low-dose thin-section CT screening, has significantly increased the detection rate of peripheral pulmonary lesions $(2,3)$. The accurate and efficient assessment and diagnosis of peripheral pulmonary 
lesions, especially malignant lesions, plays a key role in the timely treatment of the disease and patient prognosis.

At present, histopathological diagnosis of peripheral pulmonary lesions is the acceptable method of diagnosis. The main clinical methods to obtain pulmonary tissue samples include open surgery, thoracoscopic biopsy, fiberoptic bronchoscopic lung biopsy, sputum exfoliative cytology, and percutaneous needle biopsy (PNB). Open surgery and thoracoscopic biopsy have high diagnostic accuracy and are the gold standard for the diagnosis of pulmonary lesions. However, they are invasive, costly, risky, and not suitable for older patients or patients with cardiopulmonary dysfunction (4). Fiberoptic bronchoscopic biopsy is mainly applied to central bronchial lesions. However, it is difficult to access and biopsy the distal end of peripheral pulmonary lesions (5). Sputum exfoliative cytology is simple and convenient, however, the number of cells obtained is small and the positive rate is low (6). Needle biopsy, usually guided by CT or ultrasound, has high diagnostic performance, is easy to operate, and has few complications for the diagnosis of peripheral pulmonary lesions $(7,8)$. CT-guided biopsy can show the internal characteristics and adjacent relationship of the lesion, but it is expensive, cumbersome to perform, uses radiation, and requires a high body position $(7,8)$. In contrast, ultrasound-guided biopsy is low cost, multiangled, has real-time monitoring to guide the operation, does not require radiation, and has low requirements for body position $(9,10)$.

Insufficient specimen tissue or necrotic tissue components in the obtained biopsy presents a significant problem in the histopathological diagnosis of malignant and benign lesions. Unfortunately, in some studies (11-14), such undiagnosed cases are excluded which leads to overestimation of the diagnostic accuracy and sensitivity (15). In other studies, these cases may be included as negative results $(3,16)$ which underestimates the diagnostic accuracy and sensitivity (15).

The intention-to-diagnose principle (15) is used to classify cases with indeterminate results. Lesions that are finally clinically diagnosed as malignant are classified as false negatives, using the $3 \times 2$ diagnostic table, when calculating sensitivity. Indeterminate results that are finally clinically diagnosed as benign lesions are classified as false positives when calculating specificity. Schuetz et al. (15) reported that the intention-to-diagnose principle can more accurately assess the sensitivity and specificity of diagnostic tests. Lee et al. (17) used the intention-to-diagnose principle to report the diagnostic accuracy of CT-guided needle biopsies of lung lesions. However, to date, there have been no reports on the diagnostic sensitivity and specificity of US-PNBs in peripheral pulmonary lesions based on the intention-todiagnose principle.

This study assessed the diagnostic accuracy, sensitivity, specificity, PPV, and NPV of US-PNB according to the intention-to-diagnose principle (14). Factors including lesion size, different biopsy needles, and puncture times were also examined. The proportion of diagnostic failure was measured and the associated risk factors were identified.

We present the following article in accordance with the STARD reporting checklist (available at https://dx.doi. org/10.21037/apm-21-2220).

\section{Methods}

\section{Patients}

From January 2017 to December 2019, a total of 957 consecutive US-PNB procedures for peripheral pulmonary lesions in 930 patients in the Department of Ultrasound, the First Affiliated Hospital of Guangxi Medical University, China, was examined. All procedures were performed on hospitalized patients. Patients were included in this study if they: (I) underwent US-PNB and CT imagining, and postoperative biopsy specimens were examined histopathologically; (II) did not present with any contraindications prior to biopsy; and (III) could tolerate the surgical positions and cooperate with the respiratory commands during biopsy. This study was approved by the Ethics Committee of the First Affiliated Hospital of Guangxi Medical University, Nanning, China [2021(KYE-199)]. Patient informed consent was waived due to the retrospective design of this study. All procedures performed in this study involving human participants were in accordance with the Declaration of Helsinki (as revised in 2013). All patients were followed up for more than 1 year.

Contraindications for needle biopsy were as follows: (I) patients with severe emphysema and pulmonary cannon near the lesion; (II) patients with suspected vascular disease, such as pulmonary arteriovenous fistula; (III) patients with intrapulmonary cystic disease, such as pulmonary echinococcosis; (IV) patients with coagulation disorders or undergoing anticoagulant therapy; and (V) patients with uncontrolled cough, patients who cannot cooperate with surgery, or presented with severe cardiopulmonary insufficiency and pulmonary hypertension. 


\section{Ultrasound examination and puncture guidance method}

Ultrasonic examinations were performed with Logiq9 (GE, CT, USA) or AcusonS2000 (Siemens, Munich, Germany) equipped with probe frequency $2.5-4.0$ or 3.5-5.5 MHz, convex array transducers, and color Doppler. All biopsies were performed with commercially available ultrasound systems (Preirus or EUB6500, Hitachi, Tokyo, Japan) and configured puncture probes with 1-5 or 2-5 $\mathrm{MHz}$ dedicated convex-array puncture probes (EUP-B715 or EUP-B514, Hitachi). The puncture probes were configured with 3 angles $\left(0^{\circ}, 15^{\circ}, 30^{\circ}\right)$. The adjustable biopsy gun (MG1522, BARD Magnum, Bard Peripheral Vascular, Tempe, AZ, USA) was equipped with two selectable penetration depths of 15 and $22 \mathrm{~mm}$ for drawing out the specimens. Supplementary 18-gauge (18G) or 16-gauge (16G) biopsy needles (BARDMagnum Disposable Needle, Bard Peripheral Vascular) were used in all biopsies. The DS-1 medical ultrasonic coupling agent was selected (Shanghai Junkang Medical Equipment Co., Ltd., China).

Prior to biopsy puncture, the position of the patient was determined according to the location of the lesion displayed on the CT images. The concrete position, size, and internal characteristics of the target lesion were measured and evaluated by conventional ultrasonography. The blood flow distribution inside and around the lesion was determined by color Doppler flow imaging. The relationship between the lesion and the surrounding blood vessels and adjacent organs was assessed. The optimal puncture point and puncture path were determined, and the point of puncture was marked on the skin. Prior to puncture biopsy, the puncture probe was cleaned with $75 \%$ ethanol solution for 10 minutes and placed on a sterile plastic film to ensure complete sterilization.

To prepare for the puncture operation, the skin was routinely disinfected, sterile scarves were spread, and $2 \%$ lidocaine $(1-2 \mathrm{~mL})$ was applied to the puncture point to provide layer-by-layer anesthesia. The needle was inserted into the edge of the target lesion according to the predesigned puncture point and path. The patient was asked to hold their breath, and the needle was quickly pulled out after high-speed ejection of the trigger button. The tissue collected in the needle groove was entirely transferred to sterile filter paper, fixed in formaldehyde fixative and sent for histopathological examination. Intraoperative and postoperative complications such as hemoptysis, and pneumothorax and pleural reactions were monitored. All biopsies were performed by two physicians with rich ultrasonic diagnostic experience and proficiency in guiding percutaneous lung biopsies.

\section{Data collection}

Basic patient characteristics including gender, age, history of prior malignancy, and smoking history (yes or no) were collated. Data relating to the lesion included the size and lesion type (solid or multi-type), lesion location (location 1 describes the left or right lung, and location 2 describes the upper, middle or lower lobes), and final clinical diagnosis (benign or malignant). The data relating to the biopsy operation procedure included patient position (supine, lateral, or prone), needle size (16 gauge or 18 gauge), needle passes ( $\leq 2,3$, or $>3$ times), and puncture angle $\left(0^{\circ}, 15^{\circ}, 30^{\circ}\right.$, or multi-angle).

\section{Reference for relevant variables}

References for lesion size included ultrasound vectorial section scanning, the lesion shown by the image, and the maximum diameter from superficial to deep. For smoking history, a patient who has smoked less than 100 cigarettes in his lifetime was considered a non-smoker without a smoking history. A patient who has smoked more than 100 cigarettes in his lifetime but did not smoke within one month before the surgery was considered to be a former smoker. A patient who has smoked within one month before surgery was considered a current smoker. Both former smokers and current smokers were classified as having a smoking history (18). The density of the CT image and the internal characteristics of the lesions were considered in determining the type of lesion. Lesions were classified as solid or mixed. Solid lesions have homogeneous high density on CT which can mask the bronchovascular bundles. Mixed lesions have features such as ground-glass sign, bronchial sign, cavity sign, and calcifications (19).

\section{Reference standards for histopathological and final clinical diagnosis}

Histopathological results from needle biopsies were classified as malignant lesions, benign lesions, or lesions that cannot be identified. Biopsies were classified as inconclusive in cases where components of the normal respiratory system, blood, and necrotic material were all present, and in cases where there was insufficient sampling. In cases where the biopsy histopathology report indicated dysplasia, 
such lesions were considered malignant and thus, a positive result. The classification of final clinical diagnosis was based on previous studies (20). Malignant lesions were determined by histopathological examination of surgical specimens, biopsy tissue specimens, or biopsies of distant metastases, and further confirmed by follow-up imaging. If the lesion shrank or disappeared in the absence of chemotherapy and radiotherapy, or the lesion size was stable for more than 1 year, the lesion was considered benign. A true positive (TP) refers to a case in which both the histopathological findings of the biopsy and the final clinical diagnosis indicates a malignant lesion. A true negative (TN) refers to a case in which both the histopathological findings of the biopsy and the final clinical diagnosis indicates a benign lesion. A false positive (FP) refers to a case in which the histopathological findings of the biopsy diagnose a malignant lesion while the final clinical diagnosis is benign. A false negative (FN) refers to a case in which the histopathological findings of the biopsy diagnose a benign lesion while the final clinical diagnosis is malignant.

\section{Grouping of studies}

The 957 biopsy procedures were classified as diagnostic successes or diagnostic failures. The diagnostic success group included both TP and TN results. The diagnostic failure group included $\mathrm{FP}, \mathrm{FN}$, and indeterminate results.

\section{Statistical analysis}

According to the intention-to-diagnose principle (14), the sensitivity, specificity, positive predictive value (PPV), and negative predictive value (NPV) of peripheral pulmonary lesions in the diagnosis of malignant tumors were calculated with $95 \%$ confidence interval (CI).

Normal distribution continuous variables were expressed as mean \pm standard deviation (SD). Data that did not conform to normal distribution were expressed by the median or quartile, and categorical variables were expressed as frequency (percentage). To determine the risk factors for diagnostic failure, univariate analysis was performed for factors related to patients, lesions, and biopsy procedures, and $t$-tests were used for continuous variables, with adjustment for homogeneity of variance when needed. Pearson $\chi^{2}$ test or Fisher's test was used to analyze categorical variables. Variables with $\mathrm{P}<0.1$ in the univariate analysis were included in multivariate logistic regression analysis and screened by the Forward stepwise selection mode to identify independent risk factors for diagnostic failure, and a $\mathrm{P}$ value $<0.05$ was considered statistically significant. All statistical calculations were performed using the SPSS 25.0 statistical software package (IBM Corporation, Armonk, NY, USA).

\section{Results}

\section{Baseline characteristics of the study population}

A total of 930 patients underwent a total of 957 biopsies. Study cases inclusion and exclusion are summarized in Figure 1. There were 23 patients who underwent 2 biopsies of the same lesion and 2 patients who underwent 3 biopsies of the same lesion, and these repeat biopsies were counted as different events. There were 659 males and 298 females aged from 5-86 years, with a mean age of $55.7 \pm 13.54$ years. There were 490 patients with a history of smoking and 42 patients with a previous history of malignant tumors (Table 1).

\section{Diagnostic efficacy}

The US-PNB histopathology results showed that $51.7 \%$ (495/957) of the 957 cases were malignancies, $43.8 \%(419 / 957)$ were benign diagnoses, and $4.2 \%$ (40/957) were indeterminate lesions. The final clinical diagnosis determined that $59.4 \%$ (568/957) of cases were malignancies and 40.6\% (389/957) were benign (Table 2).

The overall diagnostic accuracy, sensitivity, and specificity was $90.3 \%$ (864/957; $95 \%$ CI: $0.88-0.922)$, 87.2\% (495/568; 95\% CI: 0.84-0.90), and 94.9\% (369/389; 95\% CI: 0.92-0.97), respectively. The PPV and NPV was 99.4\% (495/498; 95\% CI: 0.98-0.99) and 88.1\% (369/419; 95\% CI: 0.845-0.91), respectively (Table 3).

There were 543 lesions that were $\leq 35 \mathrm{~mm}$ and 414 lesions $>35 \mathrm{~mm}$. The diagnostic accuracy, sensitivity, specificity, PPV, and NPV of lesions $\leq 35 \mathrm{~mm}$ was $90.6 \%$ (492/543; 95\% CI: $88.1-93.1 \%), 85.1 \%$ (222/261; 95\% CI: $88.1-$ 93.1\%), $95.7 \%$ (270/282; 95\% CI: $94.0-97.4 \%), 99.6 \%$ (222/223; 95\% CI: 99.1-99.9\%), and 91.5\% (270/295; 95\% CI: 89.2-93.9\%), respectively. The diagnostic accuracy, sensitivity, specificity, PPV, and NPV of lesions $>35 \mathrm{~mm}$ was $89.9 \%$ (372/414; 95\% CI: 87.0-92.8\%), 88.9\% (273/307; 95\% CI: 85.9-91.9\%), 92.5\% (99/107; 95\% CI: $90.0-95.0 \%), 99.3 \%$ (273/275; 95\% CI: 98.5-99.9\%), and $79.8 \%$ (99/124; $95 \% \mathrm{CI}: 75.9-83.7 \%)$, respectively. The 16G biopsy needle was used in 100 cases and the $18 \mathrm{G}$ 


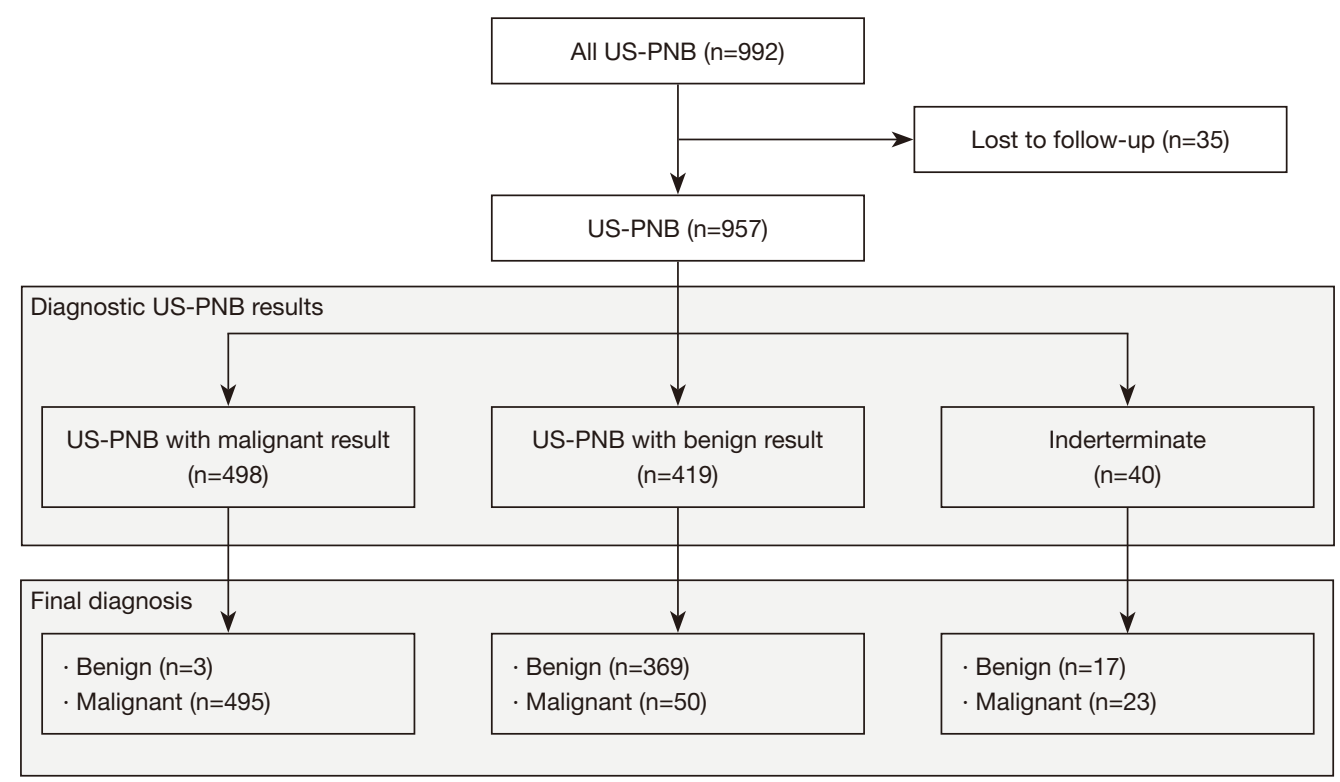

Figure 1 Inclusion/exclusion flow chart for the study. US-PNB, ultrasound-guided percutaneous needle biopsy.

Table 1 Basic characteristics of the 957 patients who underwent ultrasound-guided percutaneous needle biopsy

\begin{tabular}{lc}
\hline Characteristics & $\mathrm{n}(\%)$ \\
\hline Age (y), range (mean \pm SD) & $5-86(55.7 \pm 13.54)$ \\
Gender & $659(68.9)$ \\
Male & $298(31.1)$ \\
Female & \\
Smoking history & $490(51.2)$ \\
Yes & $467(48.7)$ \\
No & \\
History of prior malignancy & $42(4.4)$ \\
Yes & $915(95.6)$ \\
No & \\
Lesion location 1 & $433(45.2)$ \\
Left lung & $524(54.8)$ \\
Right lung & \\
Lesion location 2 & $534(55.8)$ \\
Upper lobe & \\
Middle or lower lobe & \\
Lesion size (mm), range (mean \pm SD) & \\
\hline
\end{tabular}

Table 1 (continued)
Table 1 (continued)

\begin{tabular}{lc}
\hline Characteristics & $\mathrm{n}(\%)$ \\
\hline Lesion type & $727(76.0)$ \\
Solid & $230(24.0)$ \\
Multi-type & \\
Patient position & $232(24.2)$ \\
Supine & $287(30.0)$ \\
Lateral & $438(45.8)$ \\
Prone & \\
Needle size (gauge) & $100(10.4)$ \\
16 & $857(89.6)$ \\
18 & \\
Needle passes & $251(26.2)$ \\
$\leq 2$ times & $511(53.4)$ \\
3 times & $195(20.4)$ \\
$>3$ times & \\
Puncture angle & $29(3.0)$ \\
$0^{\circ}$ & $638(66.7)$ \\
Multi-angle & \\
\hline & \\
\hline $5^{\circ}$ & \\
\hline
\end{tabular}


Table 2 Ultrasound-guided percutaneous needle biopsy diagnostic categories stratified by lesion size, biopsy needle, and needle passes

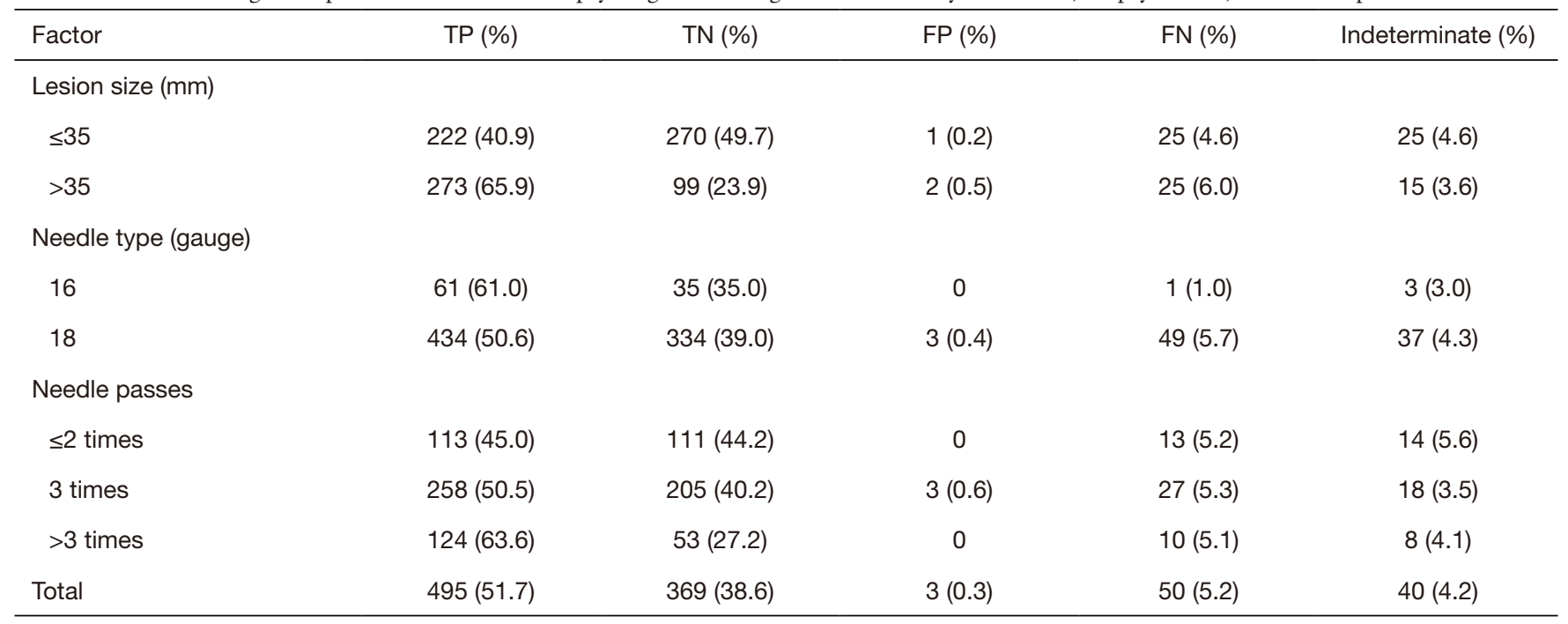

TP, true positive; TN, true negative; FP, false positive; FN, false negative.

Table 3 Ultrasound-guided percutaneous needle biopsy diagnostic efficacy stratified by lesion size, biopsy needle, and needle passes

\begin{tabular}{|c|c|c|c|c|c|}
\hline Factor & Accuracy & Sensitivity & Specificity & PPV & NPV \\
\hline$\leq 35$ & $\begin{array}{c}90.6 \%(88.1-93.1) \\
(492 / 543)\end{array}$ & $\begin{array}{c}85.1 \%(88.1-93.1) \\
(222 / 261)\end{array}$ & $\begin{array}{c}95.7 \%(94.0-97.4) \\
(270 / 282)\end{array}$ & $\begin{array}{c}99.6 \%(99.1-99.9) \\
(222 / 223)\end{array}$ & $\begin{array}{c}91.5 \%(89.2-93.9) \\
(270 / 295)\end{array}$ \\
\hline$>35$ & $\begin{array}{c}\text { 89.9\% }(87.0-92.8) \\
(372 / 414)\end{array}$ & $\begin{array}{c}88.9 \%(85.9-91.9) \\
(273 / 307)\end{array}$ & $\begin{array}{c}92.5 \%(90.0-95.0) \\
(99 / 107)\end{array}$ & $\begin{array}{c}99.3 \%(98.5-99.9) \\
(273 / 275)\end{array}$ & $\begin{array}{c}79.8 \%(75.9-83.7) \\
(99 / 124)\end{array}$ \\
\hline 16 & $\begin{array}{c}96.0 \%(92.2-99.8) \\
(96 / 100)\end{array}$ & $\begin{array}{c}93.9 \%(89.2-98.6) \\
(61 / 65)\end{array}$ & $100 \%(35 / 35)$ & $100 \%(61 / 61)$ & $\begin{array}{c}97.2 \%(94.0-99.9) \\
(35 / 36)\end{array}$ \\
\hline 18 & $\begin{array}{c}89.6 \%(87.6-91.6) \\
(768 / 857)\end{array}$ & $\begin{array}{c}86.2 \%(83.9-88.5) \\
(434 / 503)\end{array}$ & $\begin{array}{c}94.4 \%(92.9-95.9) \\
(334 / 354)\end{array}$ & $\begin{array}{c}99.3 \%(98.7-99.9) \\
(434 / 437)\end{array}$ & $\begin{array}{c}87.2 \%(85.0-89.4) \\
(33 / 383)\end{array}$ \\
\hline 3 times & $\begin{array}{c}90.6 \%(88.1-93.1) \\
(463 / 511)\end{array}$ & $\begin{array}{c}86.9 \%(84.0-89.8) \\
(258 / 297)\end{array}$ & $\begin{array}{c}95.8 \%(94.1-97.5) \\
(205 / 214)\end{array}$ & $\begin{array}{c}98.9 \%(98.0-99.8) \\
(258 / 261)\end{array}$ & $\begin{array}{c}88.4 \%(85.6-91.2) \\
(205 / 232)\end{array}$ \\
\hline$>3$ times & $\begin{array}{c}90.8 \%(86.7-94.9) \\
(177 / 195)\end{array}$ & $\begin{array}{c}89.9 \%(85.7-94.1) \\
(124 / 138)\end{array}$ & $\begin{array}{c}93.0 \%(89.4-96.6) \\
(53 / 57)\end{array}$ & $100 \%(124 / 124)$ & $\begin{array}{c}84.1 \%(79.0-89.2) \\
(53 / 63)\end{array}$ \\
\hline Total & $\begin{array}{c}90.3 \%(0.88-0.922) \\
(864 / 957)\end{array}$ & $\begin{array}{c}87.2 \%(0.84-0.90), \\
(495 / 568)\end{array}$ & $\begin{array}{c}94.9 \%(0.92-0.97) \\
(369 / 389)\end{array}$ & $\begin{array}{c}99.4 \%(0.98-0.99) \\
(495 / 498)\end{array}$ & $\begin{array}{c}88.1 \%(0.845-0.91), \\
(369 / 419)\end{array}$ \\
\hline
\end{tabular}

Data represents percentages, \%, (95\% Cl), (numerator/denominator). Cl, confidence interval; PPV, positive predictive value; NPV, negative predictive value. 
needle was used in 857 cases. The diagnostic accuracy, sensitivity, specificity, PPV, and NPV of the $16 \mathrm{G}$ needle was 96.0\% (96/100; 95\% CI: 92.2-99.8\%), 93.9\% (61/65; $95 \%$ CI: 89.2-98.6\%), 100\% (35/35), 100\% (61/61), and 97.2\% (35/36; 95\% CI: 94.0-99.9\%), respectively. The diagnostic accuracy, sensitivity, specificity, PPV, and NPV of the $18 \mathrm{G}$ was $89.6 \%$ (768/857; 95\% CI: 87.6-91.6\%), $86.2 \%$ (434/503; 95\% CI: 83.9-88.5\%), 94.4\% (334/354; $95 \%$ CI: 92.9-95.9\%), 99.3\% (434/437; 95\% CI: 98.7-99.9\%), and $87.2 \%$ (33/383; 95\% CI: 85.0-89.4\%), respectively. A total of 251 cases had $\leq 2$ biopsy punctures, 511 cases had 3 punctures, and 195 cases had $>3$ punctures. The diagnostic accuracy, sensitivity, specificity, PPV, and NPV of cases with $\leq 2$ biopsy punctures was $89.2 \%(224 / 251$; $95 \%$ CI: 85.4-93.0\%), 85\% (113/133; 95\% CI: 80.6-89.4\%), 94.1\% (111/118; 95\% CI: 91.2-97.0\%), 100\% (113/113), and 89.5\% (111/124; 95\% CI: 85.7-93.3\%), respectively. The diagnostic accuracy, sensitivity, specificity, PPV, and NPV of cases with 3 biopsy punctures was $90.6 \%$ (463/511; $95 \%$ CI: $88.1-93.1 \%), 86.9 \%$ (258/297; 95\% CI: 84.0-89.8\%), 95.8\% (205/214; 95\% CI: 94.1-97.5\%), 98.9\% (258/261; 95\% CI: 98.0-99.8\%), and 88.4\% (205/232; 95\% CI: 85.6$91.2 \%)$, respectively. The diagnostic accuracy, sensitivity, specificity, PPV, and NPV of cases with $>3$ biopsy punctures was $90.8 \%(177 / 195 ; 95 \%$ CI: $86.7-94.9 \%), 89.9 \%$ (124/138; 95\% CI: 85.7-94.1\%), 93.0\% (53/57; 95\% CI: 89.4-96.6\%), $100 \%$ (124/124), and 84.1\% (53/63; 95\% CI: 79.0-89.2\%), respectively (Tables 2,3 ).

\section{Diagnostic failures and risk factors}

There were 864 patients in the diagnostic success group (including 495 TPs and 369 TNs) and 93 patients in the diagnostic failure group (including 40 indeterminant results, $3 \mathrm{FP}$ results, and $50 \mathrm{FNs})$. The diagnostic failure rate was 9.72\% (93/957; 95\% CI: 0.08-0.12).

Univariate analysis of the failure of diagnosis of peripheral lung lesions using US-PNB revealed that the significant risk factors were smoking history $(\mathrm{P}=0.007)$, $18 \mathrm{G}$ biopsy needle $(\mathrm{P}=0.048)$, and final clinical diagnosis of malignant lesions $(\mathrm{P}<0.001)$. However, age group $(\mathrm{P}=0.16)$, gender $(\mathrm{P}=0.061)$, previous history of malignant tumors $(\mathrm{P}=0.612)$, lesion site $1(\mathrm{P}=0.813)$, lesion site $2(\mathrm{P}=0.981)$, different lesion sizes $(\mathrm{P}=0.697)$, lesion type $(\mathrm{P}=0.929)$, patient position $(\mathrm{P}=0.32)$, and number of punctures $(\mathrm{P}=0.809)$ were not significant risk factors (Table 4).

Factors with $\mathrm{P}<0.1$ in the univariate analysis, namely gender, smoking history, biopsy needle model, and final clinical diagnosis, were included in multivariate analyses. The results demonstrated that smoking history (OR 1.776; 95\% CI: 1.132-2.784; $\mathrm{P}=0.012$ ), $18 \mathrm{G}$ biopsy needle (OR 2.965; 95\% CI: $1.059-8.303 ; \mathrm{P}=0.039)$, and final clinical diagnosis of malignancy (OR 2.72; 95\% CI: 1.625-4.553; $\mathrm{P}<0.01$ ) were independent risk factors for diagnostic failure of peripheral pulmonary lesions by US-PNB. Patients with a history of smoking were 1.78 times more likely to experience diagnostic failure with US-PNB compared to patients without a smoking history. Using an $18 \mathrm{G}$ biopsy needle was 2.97 times more likely to result in USPNB diagnostic failure than using a 16G biopsy needle. Patients with a final clinical diagnosis of malignancy were 2.72 times more likely to experience US-PNB diagnostic failure compared to patients with a final clinical diagnosis of benign disease (Table 5).

\section{Discussion}

This study stratified the diagnostic efficacy of ultrasoundguided biopsy of peripheral pulmonary lesions according to the intention-to-diagnose principle and determined the risk factors for diagnostic failure. The overall diagnostic accuracy, sensitivity, and specificity was $90.3 \%, 87.2 \%$, and 94.9\%, respectively, and the PPV and NPV was $99.4 \%$ and $88.1 \%$, respectively. The diagnostic failure rate was $9.72 \%$, and the independent risk factors for diagnostic failure were smoking history, 18G biopsy needle, and final clinical diagnosis of malignant lesions.

The results of this study showed that the specificity of peripheral lung lesions in US-PNB was 94.9\% (369/389), which was lower than the $98-100 \%$ reported in some relevant studies $(3,5,21,22)$. However, the specificity in these latter studies may have been overestimated as indeterminate diagnoses were excluded $(21,22)$ or considering negative $(3,5)$. In contrast, this present study was based on the intention-to-diagnose principle (14), and thus included indeterminant results as false positives.

The results of this study showed that the PPV of peripheral lung lesions in US-PNB was 99.6\% (485/487), which was consistent with previous reports in the literature $(23,24)$. The high PPV in this study may be related to the fact that malignant lesions are mostly hard in texture and complete tissue strips were relatively easy obtained during puncture, which therefore satisfied the requirements of pathological diagnosis. However, there were false positives in this study. One patient who underwent US-PNB for the diagnosis of lung adenocarcinoma presented with largely 
Table 4 Results of univariate analysis for risk factors of ultrasound-guided percutaneous needle biopsy diagnostic failure

\begin{tabular}{|c|c|c|c|}
\hline Variables & Diagnostic success $(n=864)$ & Diagnostic failure $(n=93)$ & $P$ value \\
\hline$\leq 65$ & 649 & 76 & \\
\hline$>65$ & 215 & 17 & \\
\hline Gender & & & $0.061^{*}$ \\
\hline Female & 277 & 21 & \\
\hline Smoking history & & & $0.007^{*}$ \\
\hline Yes & 430 & 60 & \\
\hline No & 434 & 33 & \\
\hline No & 826 & 89 & \\
\hline Lesion location 1 & & & $0.813^{*}$ \\
\hline Left lung & 392 & 52 & \\
\hline Right lung & 472 & 41 & \\
\hline Lesion location 2 & & & $0.981^{*}$ \\
\hline Upper lobe & 382 & 41 & \\
\hline Middle or lobe lower lobe & 482 & 52 & \\
\hline Lesion size (mm) & & & $0.697^{*}$ \\
\hline Patient position & & & $0.32^{*}$ \\
\hline Supine & 211 & 21 & \\
\hline Lateral & 264 & 23 & \\
\hline Prone & 389 & 49 & \\
\hline Needle size (gauge) & & & $0.048^{\$}$ \\
\hline 16 & 96 & 4 & \\
\hline 18 & 768 & 89 & \\
\hline Needle passes & & & $0.809^{*}$ \\
\hline$\leq 2$ times & 224 & 27 & \\
\hline 3 times & 463 & 48 & \\
\hline$>3$ times & 177 & 18 & \\
\hline
\end{tabular}

Table 4 (continued) 
Table 4 (continued)

\begin{tabular}{|c|c|c|c|}
\hline Variables & Diagnostic success $(n=864)$ & Diagnostic failure $(n=93)$ & $P$ value \\
\hline $0^{\circ}$ & 202 & 21 & $0.99^{\$}$ \\
\hline $15^{\circ}$ & 576 & 62 & \\
\hline $30^{\circ}$ & 26 & 3 & \\
\hline Final diagnosis & & & $<0.001^{\star}$ \\
\hline Benign & 369 & 20 & \\
\hline Malignancy & 495 & 73 & \\
\hline
\end{tabular}

Table 5 Multivariate logistic regression analysis for risk factors of diagnostic failure

\begin{tabular}{lccccc}
\hline Variables & $\mathrm{B}$ & $\mathrm{SD}$ & $\mathrm{P}$ & $\mathrm{OR}$ & $95 \% \mathrm{Cl}$ \\
\hline Smoking history & 0.574 & 0.23 & 0.012 & 1.776 & $1.132-2.784$ \\
Needle size (gauge) & 1.087 & 0.525 & 0.039 & 2.965 & $1.059-8.303$ \\
Final diagnosis & 1 & 0.263 & $<0.01$ & 2.72 & $1.625-4.553$ \\
\hline
\end{tabular}

$\mathrm{B}$, coefficient of regression; SD, standard deviation; OR, odds ratio; $\mathrm{Cl}$, confidence interval.

adherent growth, some of which were papillary in nature. Lung tissue resection was performed, and postoperative pathological immunohistochemical results showed suspicious CD68 (+), CK7/NspsinA lung epithelium (+), P63 (-), low Ki-67 positive rate, CK20 (-), and CK5/6 (-). Furthermore, histomorphology was consistent with chronic inflammatory lung cancer, not supporting lung cancer. There was one case of pulmonary cell tumor. This patient had mediastinal tumor which, together with part of the right lower lung tissue, was removed during the operation. Postoperative pathology report suggested mediastinal liposarcoma. Most of the tissue from the right lower lung was inflammatory granulomatous tissue and there was a small amount of lung tissue without tumor. The cause of misdiagnosis in this patient was considered to be puncture of peripheral pulmonary lesions by US-PNB to obtain diseased tissue from the mediastinum.

This investigation showed that the NPV of US-PNB peripheral lung lesions was $88.1 \%$ (369/419), which was relatively higher than the 51-84.3 reported in the literature $(3,19,25)$. This may be due to the ability of core needle aspiration biopsies to obtain better tissue samples and superior diagnostic accuracy compared to the fine needle aspiration biopsy, especially in benign lesions (12). Fontaine-Delaruelle et al. (3) reported a NPV of only $51 \%$ in a multicenter study, presumably because both benign non-specific lesions and lesions that could not be determined due to insufficient specimens were considered negative results.

A variety of patient factors were analyzed in this study, and the results of multivariate analysis demonstrated that a history of smoking is an independent risk factor for failure of diagnosis of peripheral pulmonary lesions by USPNB (OR 1.776; 95\% CI: 1.132-2.784). Tobacco contains more than 50 carcinogenic chemicals which are activated by special enzymes in the body. These chemicals combine with macromolecular cells to produce covalent compounds capable of causing multiple gene mutations which ultimately leads to carcinogenesis (26-28). Smoking is closely related to the incidence of, squamous cell carcinoma (29). Large areas of liquefaction or coagulative necrosis tend to occur inside scaly cell carcinoma tissue, and factors such as liquefaction necrosis, inflammatory exudation, and cavitation are likely to cause needle biopsy sampling failure, resulting in diagnostic failure $(26,30)$.

Multivariate analysis identified final clinical diagnosis of 
malignant lesions as an independent risk factor for diagnostic failure. There were 93 cases of diagnostic failure in this study, including 40 cases in which a definite diagnosis could not be made, 3 cases of FP results, and 50 cases of $\mathrm{FN}$ results. Thus, diagnostic failure is mainly composed of FN results, with a high probability, and thus, the risk of diagnostic failure of malignant lesions is obvious. Similarly, Hiraki et al. (23) conducted a multivariate analysis of 1,000 cases of needle biopsy diagnostic failure and identified final clinical diagnosis of malignant lesions as an independent risk factor (OR 7.16; $\mathrm{P}=0.007)$, mainly caused by false negative cases. However, Priola et al. (31) reported that a final clinical diagnosis of benign lesions was an independent risk factor for diagnostic failure by needle biopsy (OR 2.18; $\mathrm{P}<0.001)$.

Our investigation also found that the type of biopsy needle used was an independent risk factor for diagnostic failure. The incidence of diagnostic failure using an $18 \mathrm{G}$ biopsy needle was higher than that with a $16 \mathrm{G}$ biopsy needle. The inner diameter of a $16 \mathrm{G}$ biopsy needle is $1.3 \mathrm{~mm}$ and the outer diameter was $1.6 \mathrm{~mm}$. The inner diameter of an $18 \mathrm{G}$ biopsy needle is $1.0 \mathrm{~mm}$ and the outer diameter is $1.2 \mathrm{~mm}$. Thus, the diameter of the $16 \mathrm{G}$ biopsy needle is thicker than that of the $18 \mathrm{G}$ needle, and is capable of obtaining more tissue sample, thereby, meeting the needs of pathological diagnosis. Furthermore, the $16 \mathrm{G}$ puncture is relatively thicker than the $18 \mathrm{G}$ needle, and therefore, it is easier to display and master the direction of the needle insertion, which ensures the accuracy of the puncture lesion and improves the success rate of diagnosis. However, some studies (10) have shown that there is no significant difference between the $16 \mathrm{G}$ and $18 \mathrm{G}$ biopsy needles in terms of the success rate of lung tumor puncture and diagnostic accuracy. This inconsistency with our study may be due to the larger sample in our cohort, and more independent variables were included for statistical analysis using multiple factors.

There were some limitations to this study. First, this was a retrospective study, with a certain degree of selection bias. Second, there were few complications in the study cohort and thus the effects on related complications could not be investigated. Third, the sub-centimeter lesions and their relationship with pleural length were not analyzed. Further prospective studies with more variables should be conducted in the future.

In conclusion, US-PNB has high diagnostic efficacy for peripheral pulmonary lesions and is an easy and reliable technique. A history of smoking, 18G biopsy needle, and final clinical diagnosis of malignant lesions are independent risk factors for diagnostic failure of peripheral pulmonary lesions using US-PNB. Identification of the risk factors for diagnostic failure will help reduce the failure rate of diagnosis.

\section{Acknowledgments}

Funding: This research was supported by 2015 Innovation Plan in Guangxi Special Funds Project (No. 2015 CXJHA002).

\section{Footnote}

Reporting Checklist: The authors have completed the STARD reporting checklist. Available at https://dx.doi. org/10.21037/apm-21-2220

Data Sharing Statement: Available at https://dx.doi. org/10.21037/apm-21-2220

Conflicts of Interest: All authors have completed the ICMJE uniform disclosure form (available at https://dx.doi. org/10.21037/apm-21-2220). The authors have no conflicts of interest to declare.

Ethical Statement: The authors are accountable for all aspects of the work in ensuring that questions related to the accuracy or integrity of any part of the work are appropriately investigated and resolved. All procedures performed in this study involving human participants were in accordance with the Declaration of Helsinki (as revised in 2013). This study was approved by the Ethics Committee of the First Affiliated Hospital of Guangxi Medical University, Nanning, China [2021(KY-E-199)]. Patient informed consent was waived due to the retrospective design of this study.

Open Access Statement: This is an Open Access article distributed in accordance with the Creative Commons Attribution-NonCommercial-NoDerivs 4.0 International License (CC BY-NC-ND 4.0), which permits the noncommercial replication and distribution of the article with the strict proviso that no changes or edits are made and the original work is properly cited (including links to both the formal publication through the relevant DOI and the license). See: https://creativecommons.org/licenses/by-nc-nd/4.0/.

\section{References}

1. Yang PC. Ultrasound-guided transthoracic biopsy of 
peripheral lung, pleural, and chest-wall lesions. J Thorac Imaging 1997;12:272-84.

2. Gietema HA, Wang Y, Xu D, et al. Pulmonary nodules detected at lung cancer screening: interobserver variability of semiautomated volume measurements. Radiology 2006;241:251-7.

3. Fontaine-Delaruelle C, Souquet PJ, Gamondes D, et al. Negative Predictive Value of Transthoracic Core-Needle Biopsy: A Multicenter Study. Chest 2015;148:472-80.

4. Tian S, Switchenko JM, Cassidy RJ, et al. Predictors of pneumonitis-free survival following lung stereotactic body radiation therapy. Transl Lung Cancer Res 2019;8:15-23.

5. Su W, Tian XD, Liu P, et al. Accuracy of endoscopic ultrasound-guided needle aspiration specimens for molecular diagnosis of non-small-cell lung carcinoma. World J Clin Cases 2020;8:5139-48.

6. Druzhinin VG, Matskova LV, Demenkov PS, et al. Taxonomic diversity of sputum microbiome in lung cancer patients and its relationship with chromosomal aberrations in blood lymphocytes. Sci Rep 2020;10:9681.

7. Lee SM, Park CM, Lee KH, et al. C-arm cone-beam CTguided percutaneous transthoracic needle biopsy of lung nodules: clinical experience in 1108 patients. Radiology 2014;271:291-300.

8. Fang HY, Chang KW, Chao YK. Hybrid operating room for the intraoperative CT-guided localization of pulmonary nodules. Ann Transl Med 2019;7:34.

9. Liao WY, Chen MZ, Chang YL, et al. US-guided transthoracic cutting biopsy for peripheral thoracic lesions less than $3 \mathrm{~cm}$ in diameter. Radiology 2000;217:685-91.

10. Guo YQ, Liao XH, Li ZX, et al. Ultrasound-Guided Percutaneous Needle Biopsy for Peripheral Pulmonary Lesions: Diagnostic Accuracy and Influencing Factors. Ultrasound Med Biol 2018;44:1003-11.

11. Zhao ZL, Peng LL, Wei Y, et al. The accuracy of ultrasound-guided lung biopsy pathology and microbial cultures for peripheral lung lesions. J Thorac Dis 2020;12:858-65.

12. Ocak S, Duplaquet F, Jamart J, et al. Diagnostic Accuracy and Safety of CT-Guided Percutaneous Transthoracic Needle Biopsies: 14-Gauge versus 22-Gauge Needles. J Vasc Interv Radiol 2016;27:674-81.

13. Uzun Ç, Akkaya Z, Düşünceli Atman E, et al. Diagnostic accuracy and safety of CT-guided fine needle aspiration biopsy of pulmonary lesions with non-coaxial technique: a single center experience with 442 biopsies. Diagn Interv Radiol 2017;23:137-43.

14. Meena N, Bartter T. Ultrasound-guided Percutaneous
Needle Aspiration by Pulmonologists: A Study of Factors With Impact on Procedural Yield and Complications. J Bronchology Interv Pulmonol 2015;22:204-8.

15. Schuetz GM, Schlattmann P, Dewey M. Use of $3 \times 2$ tables with an intention to diagnose approach to assess clinical performance of diagnostic tests: meta-analytical evaluation of coronary CT angiography studies. BMJ 2012;345:e6717.

16. Schreiber G, McCrory DC. Performance characteristics of different modalities for diagnosis of suspected lung cancer: summary of published evidence. Chest 2003;123:115S-28S.

17. Lee KH, Lim KY, Suh YJ, et al. Diagnostic Accuracy of Percutaneous Transthoracic Needle Lung Biopsies: A Multicenter Study. Korean J Radiol 2019;20:1300-10.

18. Lin HH, Ezzati M, Chang HY, et al. Association between tobacco smoking and active tuberculosis in Taiwan: prospective cohort study. Am J Respir Crit Care Med 2009;180:475-80.

19. Yun S, Kang H, Park S, et al. Diagnostic accuracy and complications of CT-guided core needle lung biopsy of solid and part-solid lesions. Br J Radiol 2018;91:20170946.

20. Baldwin DR, Callister ME; Guideline Development Group. The British Thoracic Society guidelines on the investigation and management of pulmonary nodules. Thorax 2015;70:794-8.

21. Takeshita J, Masago K, Kato R, et al. CT-guided fineneedle aspiration and core needle biopsies of pulmonary lesions: a single-center experience with 750 biopsies in Japan. AJR Am J Roentgenol 2015;204:29-34.

22. Choo JY, Park CM, Lee NK, et al. Percutaneous transthoracic needle biopsy of small $(\leq 1 \mathrm{~cm})$ lung nodules under $\mathrm{C}$-arm cone-beam CT virtual navigation guidance. Eur Radiol 2013;23:712-9.

23. Hiraki T, Mimura H, Gobara H, et al. CT fluoroscopyguided biopsy of 1,000 pulmonary lesions performed with 20-gauge coaxial cutting needles: diagnostic yield and risk factors for diagnostic failure. Chest 2009;136:1612-7.

24. Gelbman BD, Cham MD, Kim W, et al. Radiographic and clinical characterization of false negative results from CTguided needle biopsies of lung nodules. J Thorac Oncol 2012;7:815-20.

25. Matsui Y, Hiraki T, Mimura H, et al. Role of computed tomography fluoroscopy-guided cutting needle biopsy of lung lesions after transbronchial examination resulting in negative diagnosis. Clin Lung Cancer 2011;12:51-5.

26. Nah MA, Lee KS, Hwang TY. Association Between Atrial Fibrillation and the Risk of Dementia in the Korean Elderly: A 10-Year Nationwide Cohort Study. J Prev Med 
Public Health 2020;53:56-63.

27. Du X, Qi F, Lu S, et al. Nicotine upregulates FGFR3 and RB1 expression and promotes non-small cell lung cancer cell proliferation and epithelial-to-mesenchymal transition via downregulation of miR-99b and miR-192. Biomed Pharmacother 2018;101:656-62.

28. Xing L, Pan Y, Shi Y, et al. Biomarkers of Osimertinib Response in Patients with Refractory, EGFR-T790Mpositive Non-Small Cell Lung Cancer and Central Nervous System Metastases: The APOLLO Study. Clin Cancer Res 2020;26:6168-75.

Cite this article as: Li Q, Zhang L, Liao X, Tang S, Li Z. Ultrasound-guided percutaneous needle biopsies of peripheral pulmonary lesions: diagnostic efficacy and risk factors for diagnostic failure. Ann Palliat Med 2021;10(9):9772-9783. doi: 10.21037/apm-21-2220
29. Nejentsev $S$, Walker N, Riches D, et al. Rare variants of IFIH1, a gene implicated in antiviral responses, protect against type 1 diabetes. Science 2009;324:387-9.

30. Li L, Zhao W, Sun X, et al. 18F-RGD PET/CT imaging reveals characteristics of angiogenesis in non-small cell lung cancer. Transl Lung Cancer Res 2020;9:1324-32.

31. Priola AM, Priola SM, Cataldi A, et al. Accuracy of CTguided transthoracic needle biopsy of lung lesions: factors affecting diagnostic yield. Radiol Med 2007;112:1142-59.

(English Language Editor: J. Teoh) 